\title{
Serendipity Poetry and Play in Toy Piano composition and Four
}

\section{Pieces for Toy Piano}

Brian Inglis

Middlesex University | UK

\begin{abstract}
In this paper I draw on literature by Xenia Pestova, Antonietta Loffredo and Maggie Williams/Margaret Leng Tan, and primary research in the form of an interview with Kate Ryder (transcribed as an Appendix) exploring aspects of toy piano performance/composition and focussing on my Four Pieces for Toy Piano (2018). These pieces were commissioned by Ryder and premiered by her in London in 2018, and subsequently published and recorded. I identify themes which emerge in, and out from, this and other professional repertoire for toy piano relating to composition and performance practice: material/materiality; sonic character, notation, collaboration and communication. I provide a poietic account of some of the processes involved in the pieces' composition and realisation in performance.
\end{abstract}

Keywords: Toy piano, Composition, Play, Found objects, Serendipity. 
oy piano practitioners have commonly referred to the alternative and playful elements
inherent in and integral to their practice and identity - that of a professional adult
musician giving concert performances on an instrument intended as a children's toy. Loffredo (2018, p.122) suggests "the presence of this small musical toy piano on the stage by itself, reminds all of us... that 'the essential nature of all musical activity is play"'. Other manifestations of this might be the toy piano as a mirror; a special perspective through which the broader contemporary music scene can be viewed, encouraging us to reflect on contemporary music practice more generally. The toy piano has even been described as a "grained" instrument (pace Roland Barthes and poststructuralist philosophy), whose "difference" from, and implied inferiority to, the normative piano is a source of special sensual charm through quirks of timbre, articulation and tuning (SMITH, 2019). The instrument's specific characteristics and quirks have been identified as potential limitations; ways in which it is restricted - but also not; the perceived restrictions can be overcome, exploited or reframed as positive qualities. Loffredo $(2018$, p. 121) hints at the serendipitous aspect here in reflecting: "The lack of intonation, unpredictable overtones, noisy mechanism and difficulties to master, are 'deficiencies' that don't seem to hinder but instead inspire this curious play-community”. The establishment of the toy piano in the 1990s as a consistently useful and serious resource for concert music can be seen as part of a broader wave of postmodern (re)habilitation of neglected and/or denigrated sound-sources; it blurs the boundaries between children's entertainment and professional musical resource in a typical postmodern fashion. Another postmodern trait is the instrument's frequent association with multimedia elements - not just combination with other instruments (toy or not), but visual/theatrical elements and extended sound-sources, often electronic. While I would therefore explicitly link the toy piano with postmodern aesthetics, other perspectives - not necessarily mutually exclusive - include Ryder's (2019, section 5) linking of the instrument with the experimental tradition, clearly justified through the John Cage connection; and Loffredo's (2018, p.120) speculation: "Perhaps there was a need to wait for the interest in timbre which has characterised compositional research during and since the twentieth century, plus the advent of electro-acoustic music, another sound world in which the toy piano is often collaborating”. 


\section{Collaboration and exploration}

The composition processes behind my Four Pieces for Toy Piano, and their realisations, were the outcome of a collaborative relationship which is summarised by Ryder (2019, section 5) in more general terms as: "that important interim stage. The first step is to listen to the instruments, and there's the other major step of trying things out, saying does this work? and being delighted when it does work". Williams (2007) quotes Margaret Leng Tan, who notes that: "A successful work for toy piano is one that capitalises on what the instrument has to offer... it has to exploit the qualities of the instrument, or why bother?” Ryder (2019, section 6) goes further, in talking of an authentic new keyboard repertoire for toy pianos, defined as pieces which are: "written specifically for these instruments and for me, my personality, how I might stack them and how I might do them", describing this as "the really fascinating thing".

So what are the qualities of the instrument? Following on from the features identified by Loffredo above, Ryder (2019, sections 5, $6 \& 8$ ) talks of it as: "a contemporary instrument - a new instrument" which is "very much part of the experimental genre" in that "It's re-inventing something; listening to something differently”. Besides the limited, varying ranges, key sizes and dynamic possibilities, Pestova (2017, p.31) identifies the tuning as being unstable, though Ryder (2019, section 2/4) proposes alternatively that: "It can be slightly microtonal, and... that's a great attraction...”.

One thing Ryder, Pestova, Tan and Loffredo have all noted is the use of extraneous sound sources to expand the toy piano soundworld - sometimes to theatrical effect. These commonly include voice or electronics. Isabel Ettenauer (WILLIAMS 2007) cites Karlheinz Essl (2005) in the latter regard; an example of the former is Joe Cutler's La maison de Fred (2001). Turning to my own pieces, let us first consider the second movement, Laugh.

\section{Laugh}

This short movement has (unsurprisingly) the character of a scherzo. It is derived from a concrete poem of the same name by Derek Shiel, the late Irish artist and writer (see figure 1). 
FIGURE 1 - Derek Shiel (1939-2017), LAUGH.

AH HA

AAH AHA

HA HA HA HAHA

HAW

AAH HA HAHA

HEY

HAHA HAW

$\mathrm{HAH}$

AAH AHA

HE HE HAH HEY

HOHO HA HI HAHE

HUM HUM HO

HOHUM HO

HA HO HAW

HI HAH AAH

HA HA

HEW

HAHA HEHE HOHO

HI HI HI HI

HI HI HA

HEW

HUH HEY

HO HUM HOHO

HUHUH

HO HA

HA HUH

Source: SHIEL (2011, pp.22-23) 
In itself this poem was inspired by Umberto Boccioni's Futurist painting, La Risata (figure 2).

\section{FIGURE 2 - La Risata.}

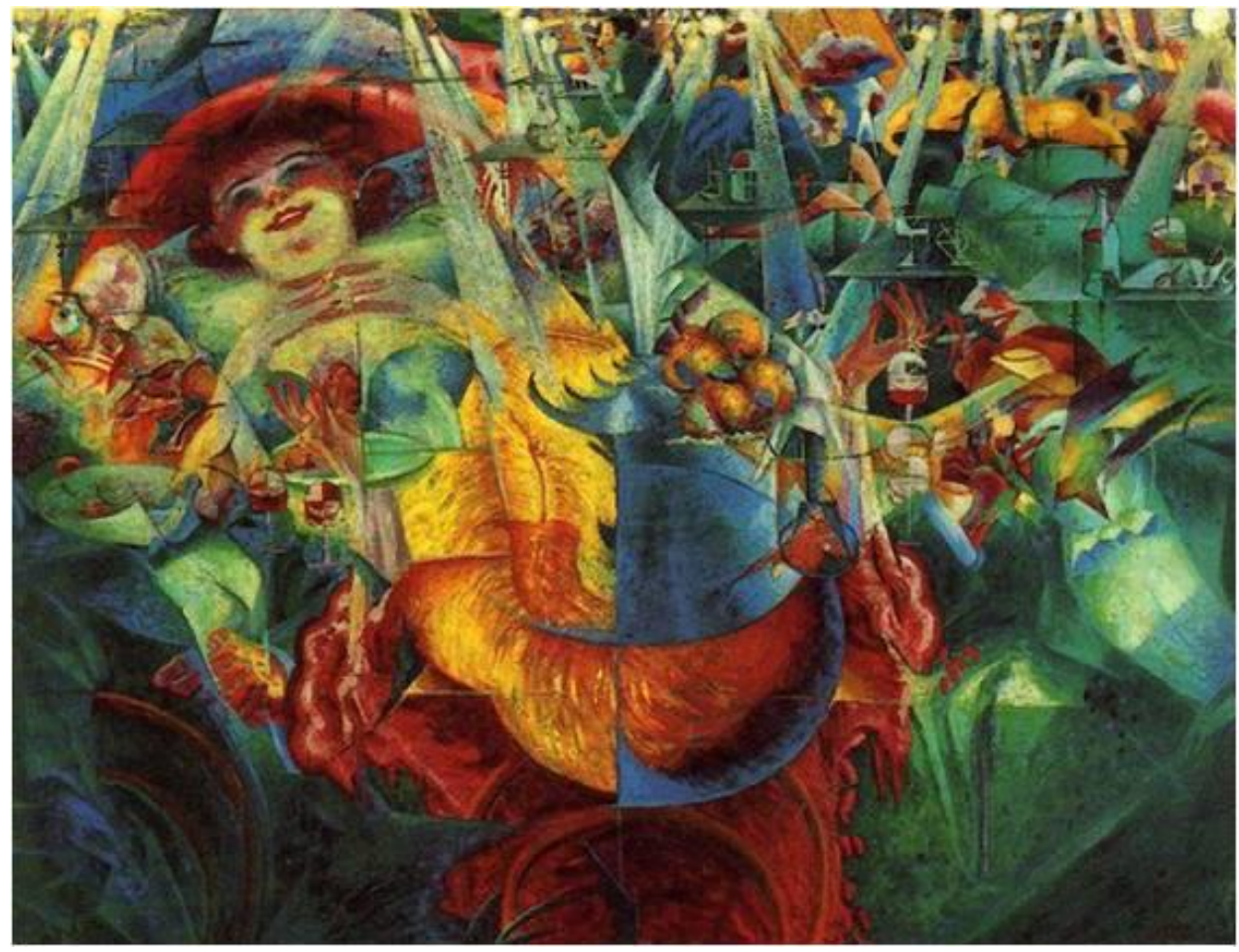

Source: BOCCIONI (1911) Public domain

Having decided to use the poem, the piece came very quickly and spontaneously, in a manner suggested by the poem's structure. Using a simple cipher expanded from the type used by Robert Schumann and other Romantic composers, I allocated each letter used in the poem to a musical note, always at the same pitch level (helpful given the limited range of toy pianos): figure 3. Rhythms are derived from the number of letters in each word. This systematic process could have generated the piece in its entirety, but it occurred to me that having the performer recite the words of the poem between the musical groups (see figure 4) would make the piece more fun, more memorable, more theatrical, and really bring it to life. So the text is conveyed by two means - in a way which is private, coded and implicit, and in a way which is extrovert and entirely explicit.

FIGURE 3 - Mapping of letters used in poem LAUGH to pitches used in composition.

\begin{tabular}{cccccccccc}
\hline Letters: & A & H & W & E & Y & O & I & U & M \\
\hline Pitches: & A & B & C\# & E & D\# & F\# & G\# & Bb & C \\
\hline
\end{tabular}


FIGURE 4 - Score page image of Laugh.

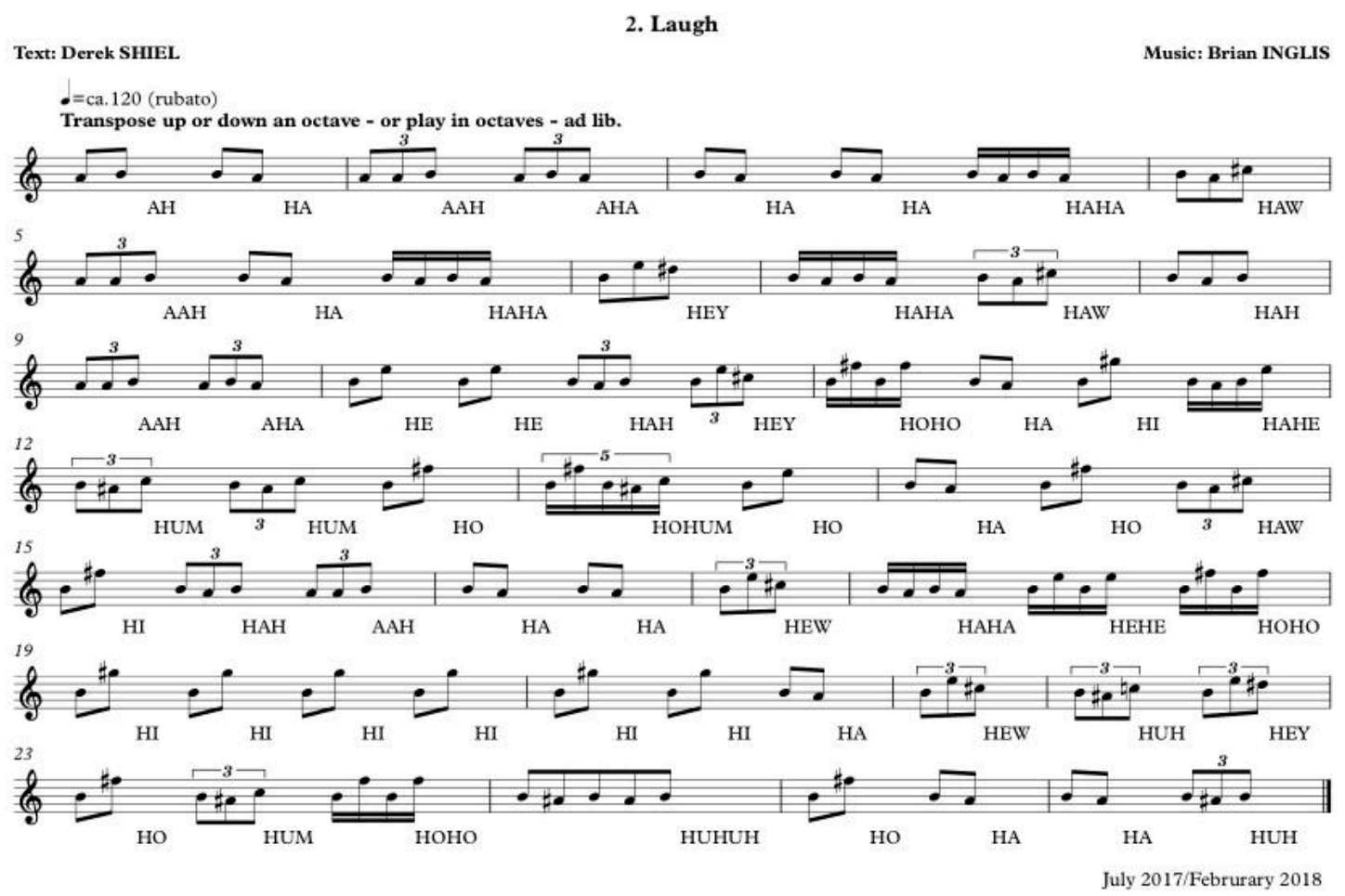

Source: INGLIS (2018, p. 7)

The realisation of the spoken text gives considerable leeway to the performer. Bearing in mind Ryder's comment about authentic repertoire, and her personality, I knew she would bring this off with great aplomb. ${ }^{1}$ And her success here is borne out by the following comment on the piece: "it enabled me to go really crazy within a certain discipline; a delight” (2019, section 7). Like Wolfe (1996), Laugh exploits the instrument's potential for humour, though this is:

not to be confused with not taking it seriously, a bit of a joke. I think particularly when you're working with instruments that are originally toys, you have to have a serious approach, because the composers I work with have never treated them as some kind of joke, but as an alternate soundworld, and that's the difference. (RYDER, 2019, section 6).

Loffredo (2018, p. 101) contextualises this by observing: "A thread of humour in the use of toy instruments runs through to today but with a slight difference. In the past it was more joking and poking fun... whereas now associative humour prevails”. Ryder (2019, section 8) develops her point

\footnotetext{
${ }^{1}$ Ryder's studio recording of this movement has been commercially released (INGLIS, 2020).
} 
in commenting that: "in a wonderful way [the toy piano] cuts through any kind of pretention. But (...) it is an instrument, and not a toy". This also connects with Ryder's position on the instrument being valorised in particular by and within the experimental tradition associated with John Cage: "I think Cage validated it immediately, because by the stage [of writing his Suite for Toy Piano] he'd won the argument with the prepared piano for a decade". The argument referred to being that all potential sound sources and modifications thereof should be included and welcomed into Cage's - and others' - compositional practice.

\section{Beautiful Lofty Things}

Beautiful Lofty Things, the third movement of my suite, follows Laugh in two ways. Firstly, it invokes the work of an Irish artist - in this case, the celebrated poet and politician William Butler Yeats. Secondly, it extends the use of a musical cipher, this time into a comprehensive and more systematic "communicable language" of the type employed by Messiaen (1969). Although the title is taken from another Yeats poem, the content is drawn from Yeats' name and his better-known poem Sailing To Byzantium.

This time all 26 notes of the alphabet are linked with the full chromatic gamut in an entirely abstract way; figure 5 .

FIGURE 5 - Mapping of letters to pitches in Beautiful Lofty Things.

\begin{tabular}{ccccccccccccc}
\hline $\mathrm{A}$ & $\mathrm{B}$ & $\mathrm{C}$ & $\mathrm{D}$ & $\mathrm{E}$ & $\mathrm{F}$ & $\mathrm{G}$ & $\mathrm{H}$ & $\mathrm{I}$ & $\mathrm{J}$ & $\mathrm{K}$ & $\mathrm{L}$ & $\mathrm{M}$ \\
\hline $\mathrm{C} \#$ & $\mathrm{D}$ & $\mathrm{D} \#$ & $\mathrm{E}$ & $\mathrm{F}$ & $\mathrm{F} \#$ & $\mathrm{G}$ & $\mathrm{G} \#$ & $\mathrm{~A}$ & $\mathrm{Bb}$ & $\mathrm{B}$ & $\mathrm{C}$ & $\mathrm{C} \#$ \\
\hline & & & & & & & & & & & & \\
\hline $\mathrm{N}$ & $\mathrm{O}$ & $\mathrm{P}$ & $\mathrm{Q}$ & $\mathrm{R}$ & $\mathrm{S}$ & $\mathrm{T}$ & $\mathrm{U}$ & $\mathrm{V}$ & $\mathrm{W}$ & $\mathrm{X}$ & $\mathrm{Y}$ & $\mathrm{Z}$ \\
\hline $\mathrm{D}$ & $\mathrm{D} \#$ & $\mathrm{E}$ & $\mathrm{F}$ & $\mathrm{F} \#$ & $\mathrm{G}$ & $\mathrm{G} \#$ & $\mathrm{~A}$ & $\mathrm{Bb}$ & $\mathrm{B}$ & $\mathrm{C}$ & $\mathrm{C} \#$ & $\mathrm{D}$ \\
\hline
\end{tabular}

In terms of Piercian semiotics, this is a symbolic sign system. The musical spelling-out of William Butler Yeats' name occurs both vertically (in the repeated chords which preface the piece) and horizontally, in the linear gesture used as a kind of refrain - see figure 6. (Again, the rhythm is linked to the lengths of the words.) It may be interpreted as a kind of emblematic tribute - just as Laugh and the Prelude were written in memory of Derek Shiel. 


\section{Water and Stone: Notation and performance}

The fourth movement, Water and Stone, offers some novel strategies for notation and performance. The conceptual principles are related to the world of natural and organic elements. An optional accompanying soundtrack consists of field recordings of water sounds recorded in Georgia in August 2017: fountains in the capital Tbilisi, and night-time rain in Mestia, in the mountainous region of Svaneti. When it comes to the notated score, a graphic strategy is employed (see figures 8 and 10). While graphic notation generally forms an important strand within my practice and research, ${ }^{2}$ using the technique in the specific context of this movement had a twofold rationale (as will be explored in this section). Firstly, to extend and develop the kind of performer freedom essayed in Laugh; and secondly to efficiently notate clusters of different kinds. The score has a tangibly tactile relationship with natural phenomena: trees, stones, crystals. Some of the graphics are traced from close-up photographs of branches (see fig. 7 and fig. $8,6^{\text {th }}$ system) and of pebbles (figs 9-10). Other graphics are drawn around templates formed by cut crystals (figure 11).

\footnotetext{
${ }^{2}$ See for instance the graphic score cadenza for my Concerto for Piano Solo (Homage to Alkan), Composers Edition 2015; and my paper Towards an analytical framework for graphic scores, and a proposed typology (online at http://eprints.mdx.ac.uk/25905/).
} 
FIGURE 6 - Beautiful Lofty Things score page image.

8

\section{Beautiful Lofty Things}
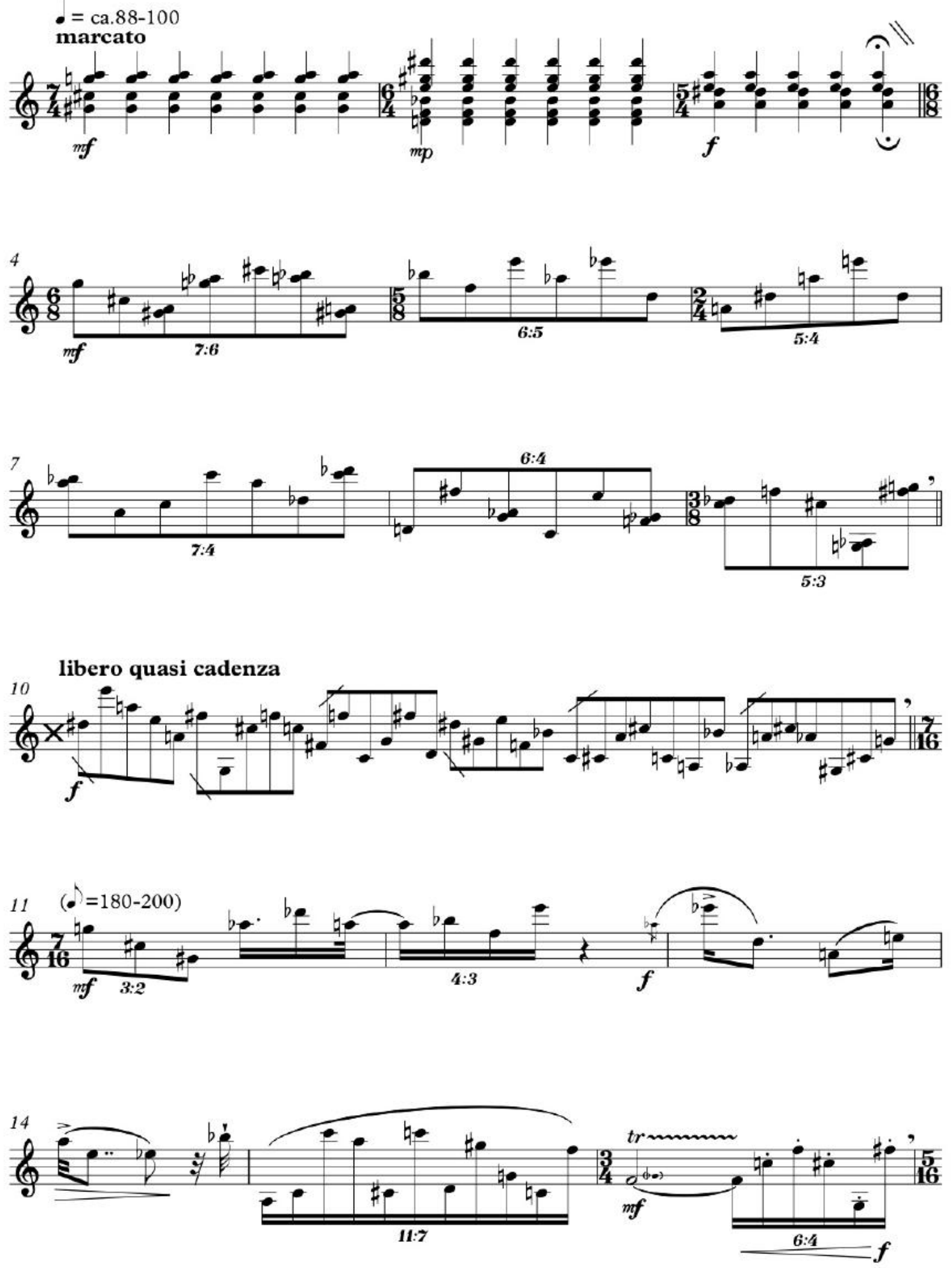

Source: INGLIS (2018, p. 8) 
INGLIS, Brian. Serendipity Poetry and Play in Toy Piano composition and Four Pieces for Toy Piano. Revista Vórtex, Curitiba, v.8, n.2, p.

FIGURE 7 - Branch photograph, source material for Water and Stone graphic score.

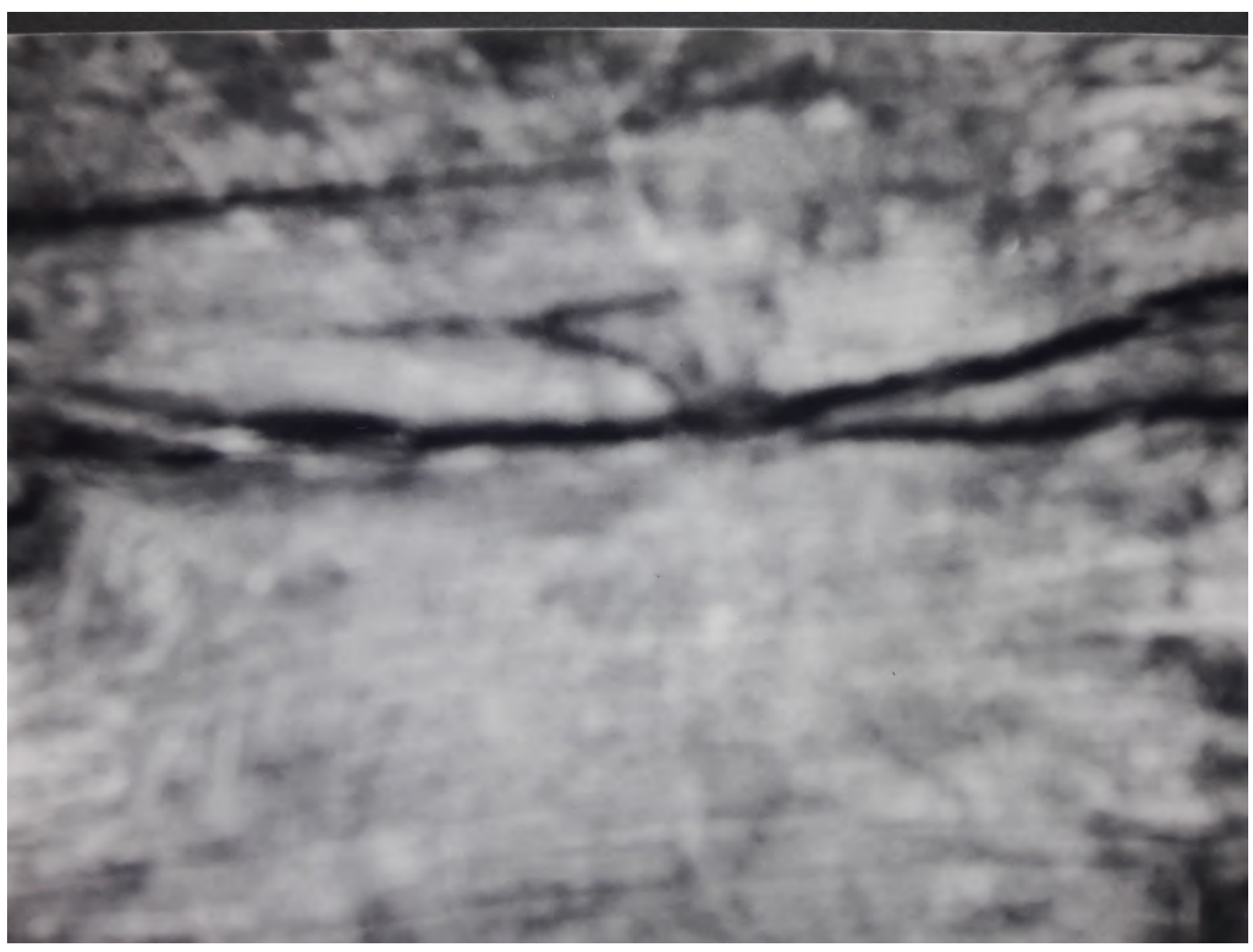

Photo credit: Brian Inglis (2017) 
FIGURE 8 - Water and Stone score page image.

10

4. Water and Stone
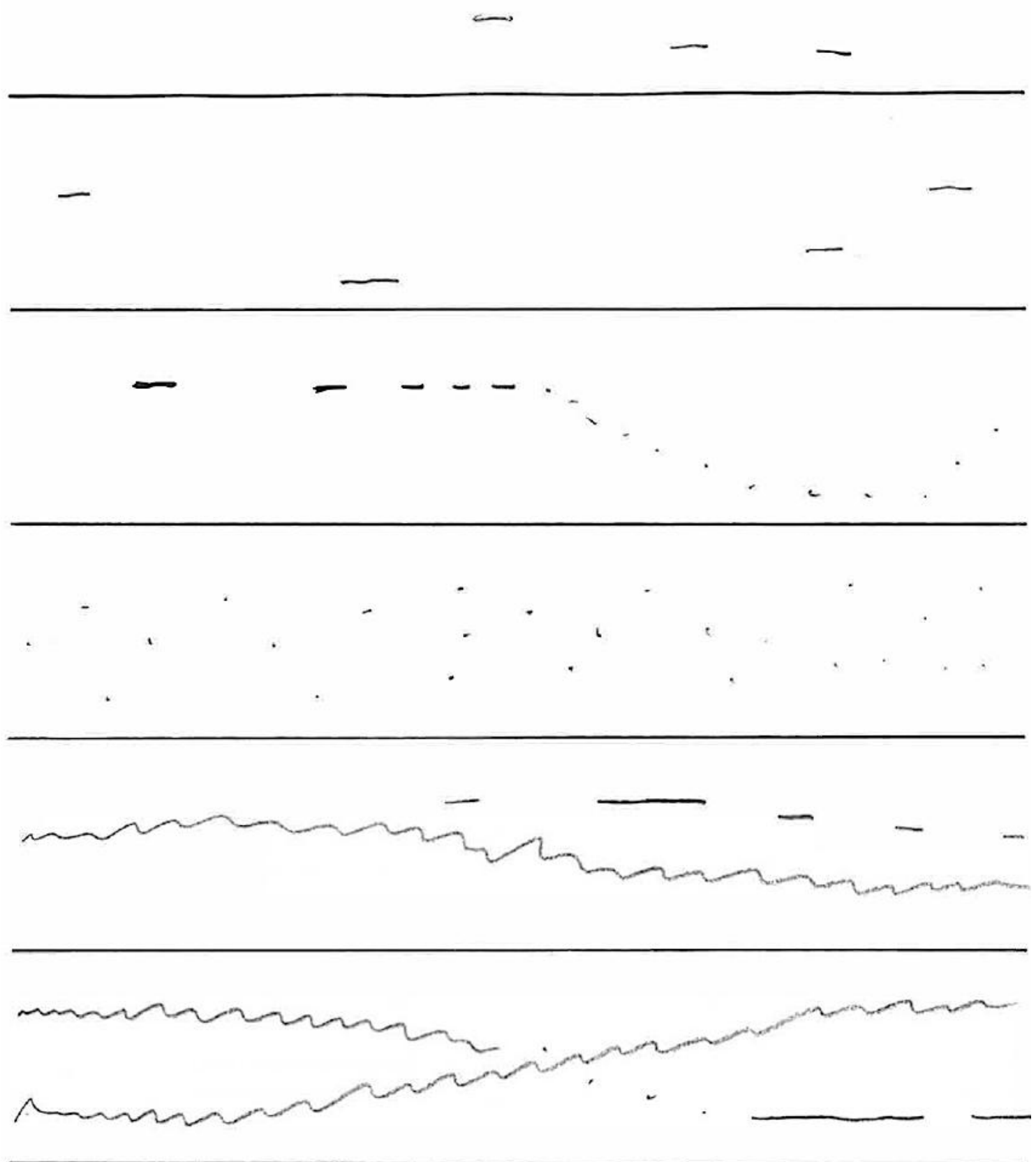

$\sim$

$\sim$

2

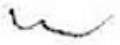

Source: INGLIS (2018, p. 10) 
FIGURE 9 - Pebble photograph, source material for Water and Stone graphic score.

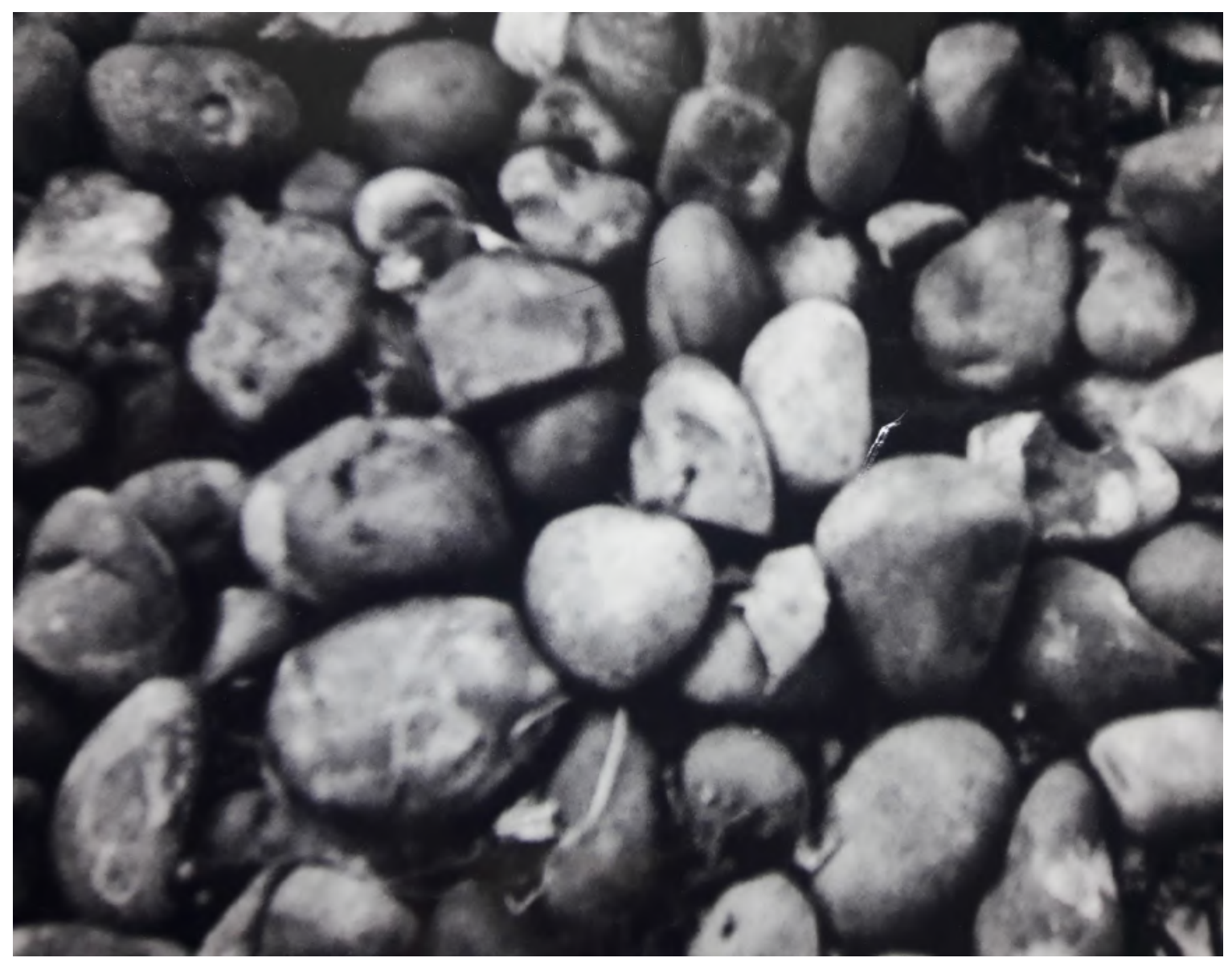

Photo credit: Brian Inglis (2017) 
FIGURE 10 - Water and Stone score page image.
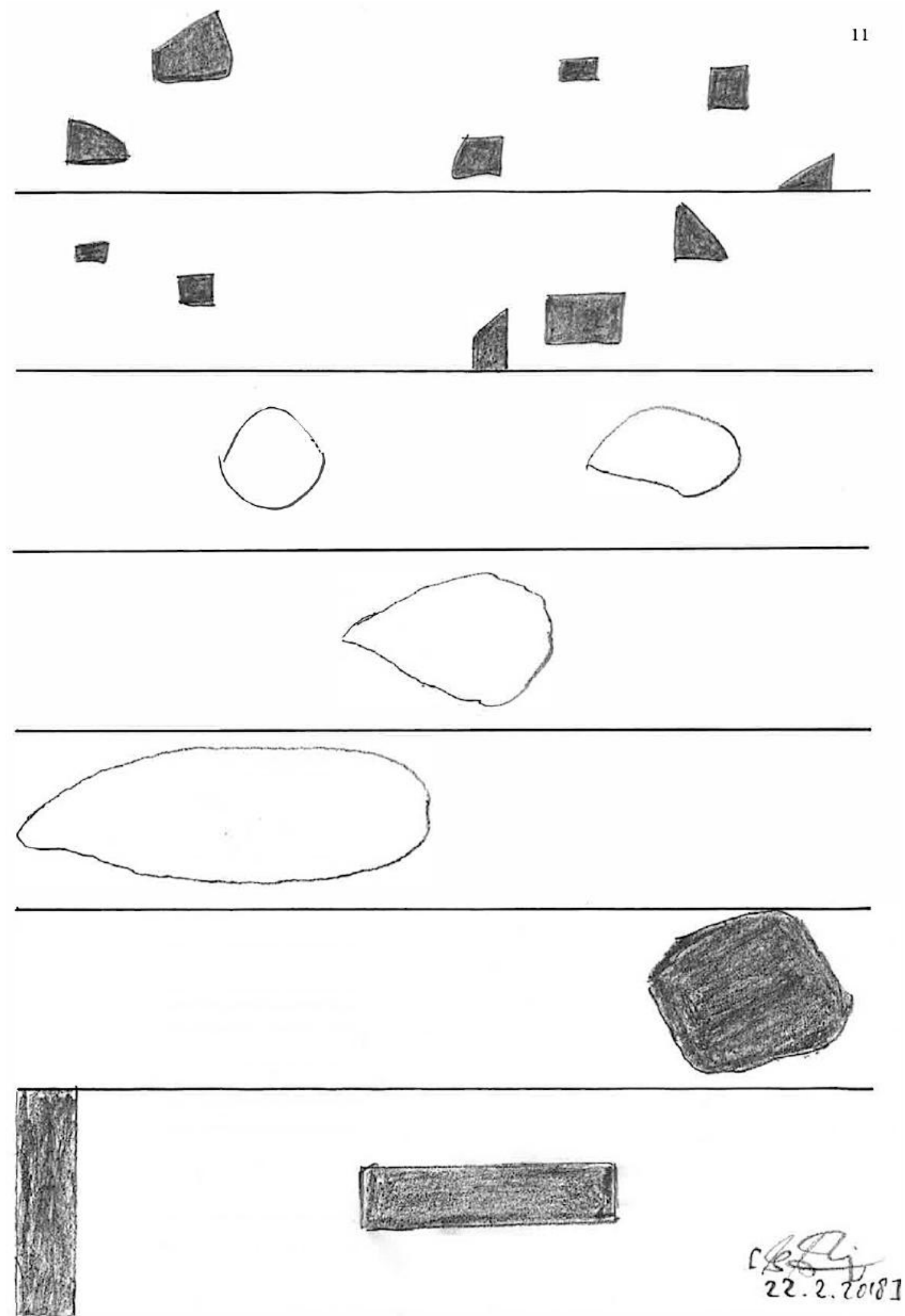

Source: INGLIS (2018, p.11) 
FIGURE 11 - Crystals used as templates for Water and Stone graphics.

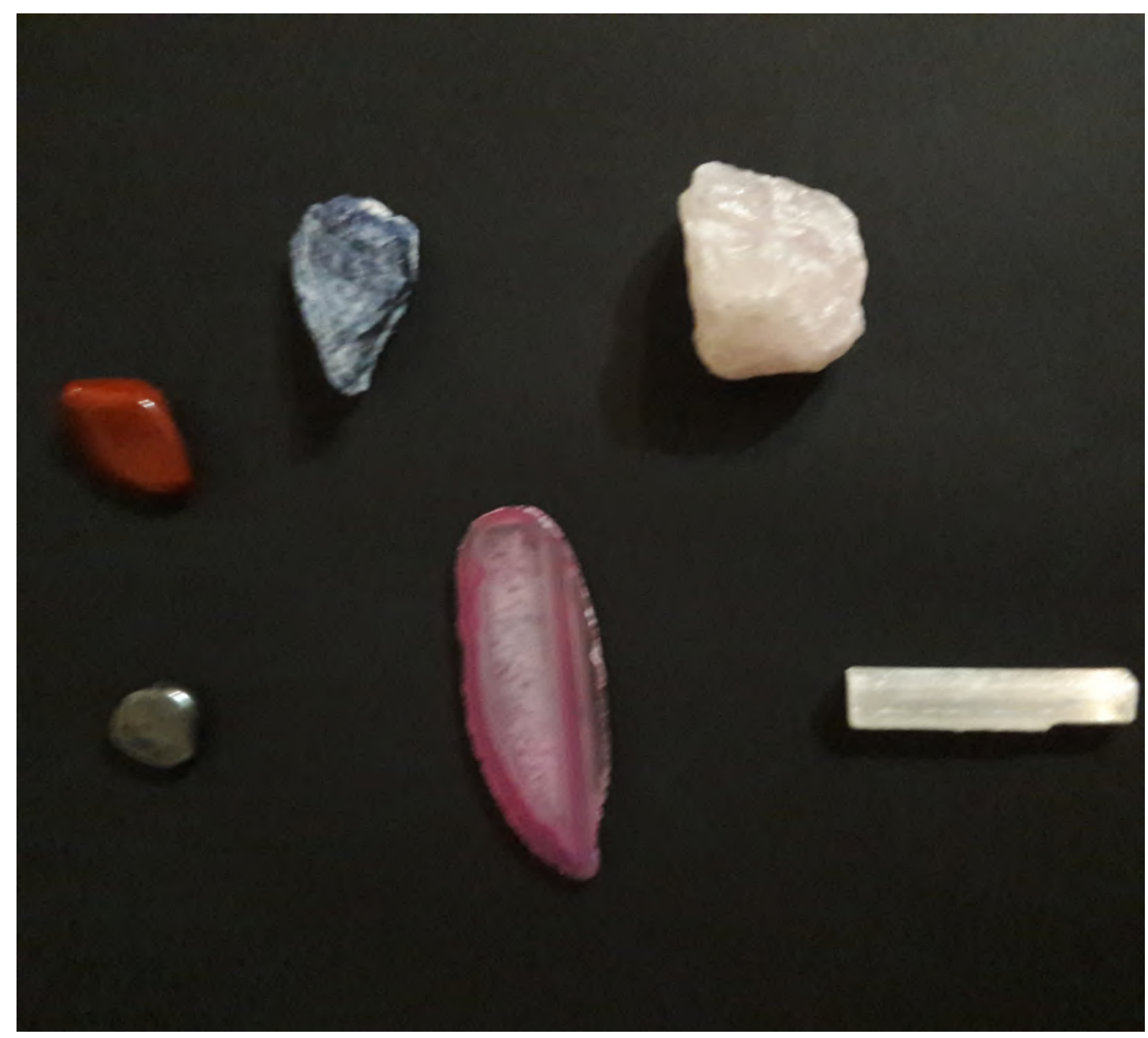

Photo credit: Brian Inglis (2020)

The resultant graphic shapes denote clusters of different kinds - chromatic, diatonic, expanding, contracting. The contexts for such realisations are varied, but highlight some of the more general advantages of graphic notation. For instance, in some early piano works by Schumann, such as Papillons (figure 12), the composer indicates the gradual reduction of a chord to one note. In conventional notation this is somewhat cumbersome. In graphic notation, this effect - and the opposite one of gradually increasing a chord's density - can be achieved with great directness and simplicity, even if the specificity is less. 
FIGURE 12 - Robert Schumann, Papillons op.2 (1832), ending.

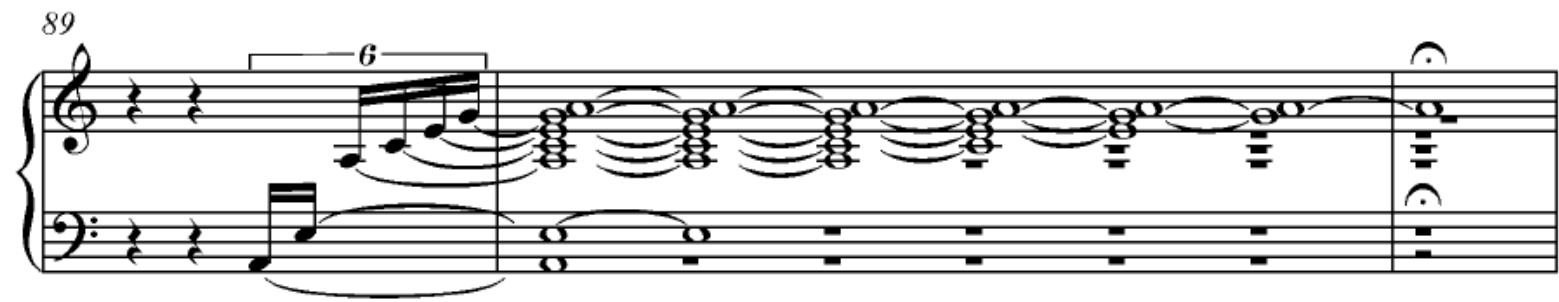

\section{Source: HERTTRICH (2009, p.30)}

Similar strategies can be found in a more contemporary context in examples by Ligeti and Cage. Notations $\mathrm{T}$ and $\mathrm{Z}$ from Cage (1960) show a variant, where the focal pitch of a cluster is shown conventionally on a stave, but the shifting limits of the clusters are indicated as graphic "islands":

FIGURE 13 - Notation T from Cage, Concert for Piano and Orchestra, Edition Peters No. 6705

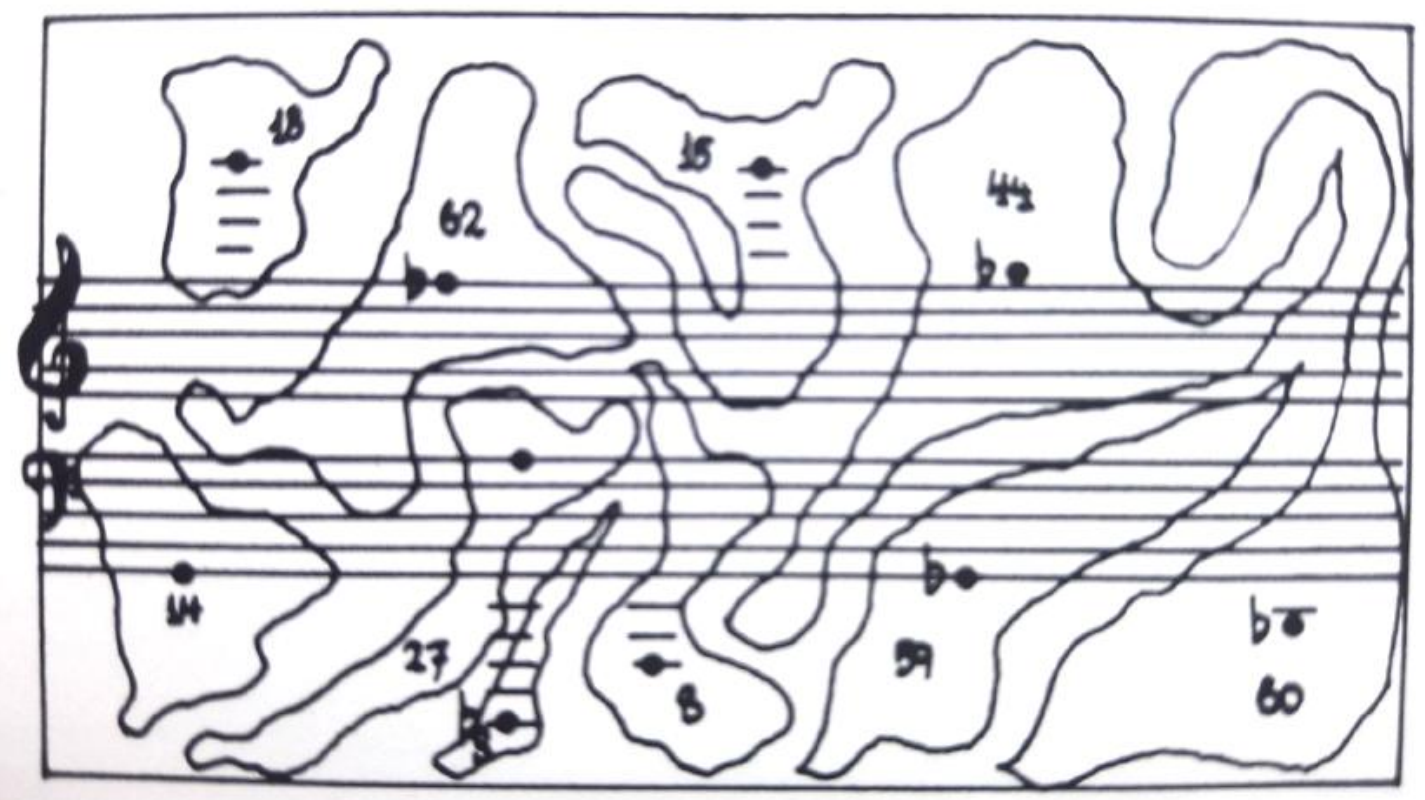

Source: CAGE 1960. (C) 1960 by Henmar Press Inc., New York. Reproduced by permission of Peters Edition Limited, London.

Ligeti's organ composition Volumina (1962) consists entirely of clusters of different types, and is notated purely graphically, without recourse to any conventions apart from the relative positions on the page of right hand, left hand and pedal (see figure 14). Ligeti also, in a relatively precise way, indicates the expansion and contraction of chromatic and diatonic clusters, and their movement: 
FIGURE 14 - Ligeti, Volumina for organ, excerpt from Edition Peters No 5983

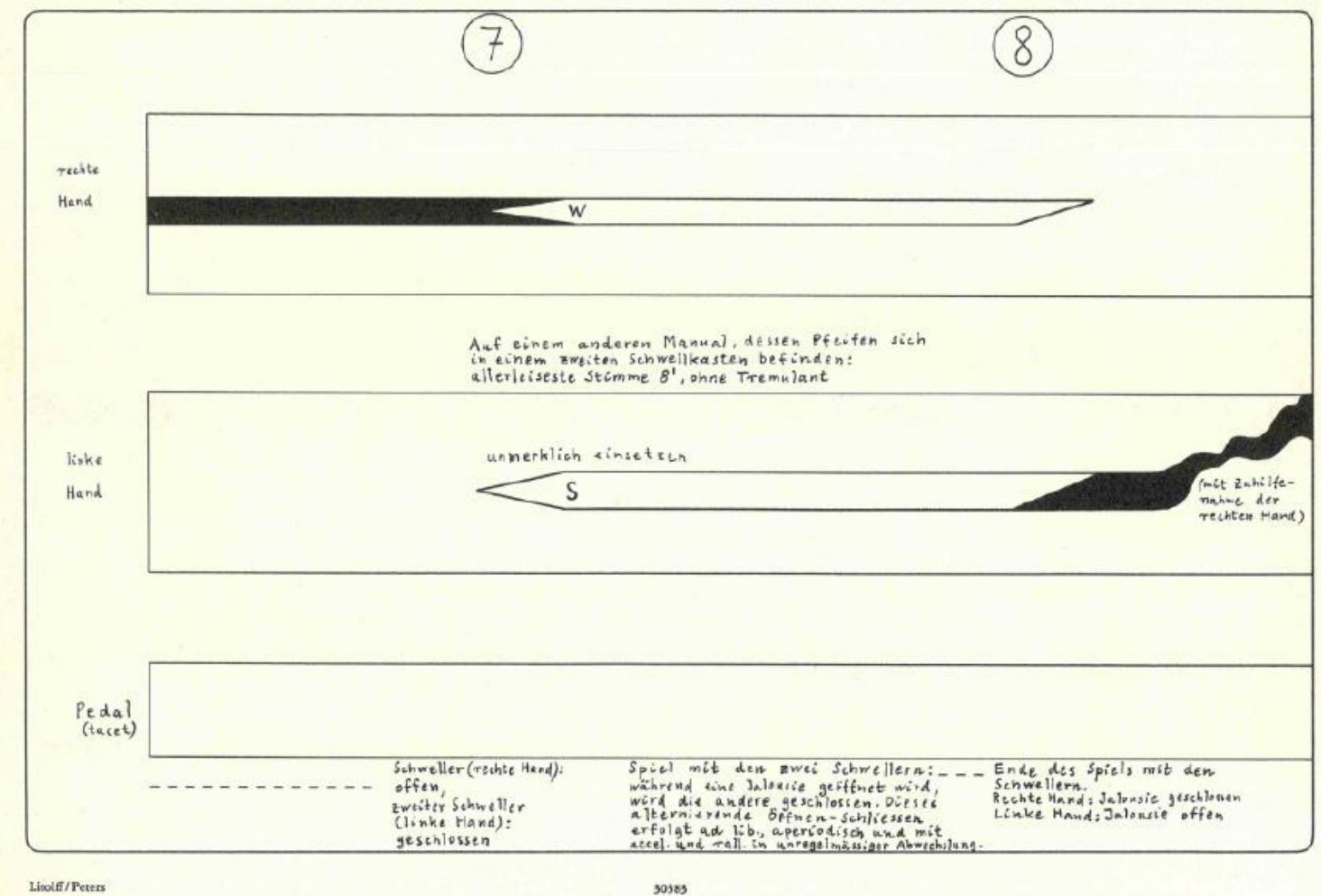

Source: LIGETI (1962, p. 7) @ 1962 by Henry Litolff's Verlag, Leipzig. Reproduced by permission of Peters Edition Limited, London.

Pestova (2017, p. 31) counsels against thick chords in toy piano writing, maintaining that: "Additive resonance of the rods contributes to the general thickness of texture, and the most successful repertoire tends to work with rather than against these limitations, avoiding thick textures and heavy, dense harmonies”. Yet in the case of clusters, sonic saturation is rather the point, so if anything, this limitation - if it is that - enbances the effect. For me, working with such material was also a way of avoiding the excessive prettiness of some toy piano repertoire and performance styles also alluded to by Ryder (2019, section 6).

Another effect of the graphic notation is the paradoxical relationship engendered between flexibility and specificity. Graphic or indeterminate notation is particularly suited to the toy piano 
medium, as the issue of restricted and variable ranges is dissipated, if not dissolved. ${ }^{3}$

This has implications for the realisation of Water and Stone, as the smaller the range of the instrument employed, the more specific the notation will be, given fixed system heights and the understanding that each system denotes the full range of the instrument. As a phenomenon I find this aesthetically neutral, though it certainly both relates to and enhances the sense of serendipity which is part of the culture of acquiring and collecting the instruments. As Ryder (2019, section 10) advises prospective toy pianists: "it's... very appealing to look around junk shops, antique shops and... sales.... You have to like them as [literally found] objects”. The serendipitous use of various kinds of found object finds an echo in the employment of natural materials in Water and Stone.

Thoughts on performing Water and Stone are encapsulated in Ryder's (2019, section 9) comment that it: "gives a lot of leeway and yet in some ways is incredibly difficult... having to play it within a certain timeframe. And this is one where (...) absolutely, you would have to work closely with the composer”.

\section{Concluding thoughts: performance and audience}

A final thought relates to the audience for toy piano compositions. There are growing toy piano "scenes" in the USA, Europe and East Asia where professional, amateur and student pianists and composers share their work in concerts, festivals and conferences/conventions. Moreover the instrument has a particular ability to "cut through" to more general, less specialised audiences, seeming more accessible than forms of contemporary music using the conventional instruments of Western classical music. This is not necessarily due to musical languages, as composers drawn to write for toy piano cover a wide stylistic field, and tend to use their own compositional idiolects rather than "writing down" for the instrument, notwithstanding a certain attraction to childhood topics (see Ryder 2019 section 6). Perhaps toy piano composers and performers are (almost inevitably) more drawn to and from the experimental tradition, as already discussed, which tends to be more aware,

\footnotetext{
${ }^{3}$ For another example of graphic notation intended for toy piano see for instance Blom (2014). Smith (2019) compares the "sensual" communication inherent in graphic notation with the "semantic" language of common practice notation (CPN), again echoing Roland Barthes' (1984, p.182) concept - following Julia Kristeva - of geno-song and pheno-song.
} 
and inclusive, of the audience. The presence of the sound source outside the realm of high art music - in childhood and popular culture (such as the Peanuts cartoon strips) - increases its relatability, in particular, obviously, to children. ${ }^{4}$

Extra-musical elements such as the visual, theatrical and comic provide a "way in" for audiences unfamiliar with contemporary music but accustomed to contemporary culture more generally. In essence, the joy of the practice is that no-one and nothing is excluded: "the fact that music is played with a toy suggests to the listener that something different will happen and they will have a chance to 'join the game'... even if they are not 'an expert'” (LOFFREDO 2018, pp. 121-22).

\section{ACKNOWLEDGMENTS}

I would like to thank Kate Ryder, for generosity with interview time (and indeed in preparing for performances and recordings); and Sam Roberts of Composers Edition, for assistance with score page images.

\section{REFERENCES}

BARTHES, Roland, trans. HEATH, Stephen. Image/Music/Text. Flamingo edition. London: Fontana, 1984.

BLOM, Diana. Biffo in the Toy Box, for toy piano and music box. In Strange Terrain: a new anthology of New Zealand graphic scores 1965-2012. Wellington: Wai-te-ata Music Press, 2014.

BOCCIONI, Umberto. La Risata, 1911. Painting.

CAGE, John. Concert for Piano and Orchestra. New York: Henmar Press, 1960. Score.

CUTLER, Joe. La maison de Fred. 2001. Score. For playing, speaking, singing and whistling toy piano.

ESSL, Karlheinz. Kalimba. 2005. Score. For toy piano and playback.

HERTTRICH, Ernst, ed. Schumann: Complete Piano Works, Volume 1. München: Henle Verlag, 2009. Score.

\footnotetext{
${ }^{4}$ An example is Seriously or jokingly? Toy piano composition workshop for early stages, conducted by Mercedes Zavala with pupils of Antonietta Loffredo from the middle sate school I.C. Cernobbio, described in the paper From Piano to Toy Piano: Composing as a Rite of Passage, MUSIC AS PLAY, 2019, Como.
} 
INGLIS, Brian. Four Pieces for Toy Piano. Chipping Norton: Composers Edition, 2018. Score. . Laugh. Performer: Kate Ryder. In compilation album I hope this finds you well in these unusual times Vol. 1. London: Nonclassical, 2020. Online at https://nonclassical.bandcamp.com/album/i-hope-this-finds-you-well-in-these-strange-times-vol-1 LIGETI, György. Volumina. Leipzig: Henry Litolff's Verlag, 1962. Score. For organ.

LOFFREDO, Antonietta. The Toy Piano. Bologna: Ut Orpheus, 2018.

MESSIAEN, Olivier. Méditations sur le mystère de la Sainte Trinité. Montrouge: Alphonse Leduc, 1969. Score. For organ.

PESTOVA, Xenia. Toy Pianos, Poor Tools: Virtuosity and Imagination in a Limited Context. Tempo, Cambridge, 71/281, 27-38, July 2017.

RYDER, Kate. London, June 2019. Interview (see transcription in Appendix).

SHIEL, Derek. Poems. London: Lulu, 2011.

SMITH, Paul. Subversive Sounds: Toy Piano and Voice as Counterhegemonic forces in The City/The Forest. Paper delivered at MUSIC AS PLAY, 2019, Como.

WILLIAMS, Maggie. Child's Play. International Piano, London, March/April 2007. Available at www.isabelettenauer.com/en/reactions/childs-play-international-piano.

WOLFE, Julia. East Broadway. 1996. Score. For toy piano and toy boombox.

\section{ABOUT THE AUTHOR}

Born in Münster, Germany, of Scottish and Irish heritage, Dr Brian Andrew Inglis is Senior Lecturer at Middlesex University, London, UK, where he is Programme Leader for BA Music. A composer and musicologist, his practice and research explore overarching themes of genre and identity. Recent outputs include an album of solo piano music Living Stones (Sargasso), and an edition (with Barry Smith) of Kaikhosru Sorabi's Letters to Philip Heseltine (Peter Warlock), published by Routledge in 2019. A chapter on John Tavener's To a Child Dancing in the Wind is forthcoming in Heart's Ease (Peter Lang 2020). He is a member of the Editorial Board for the Journal of the Royal Musical Association (UK), and on the steering committee of the international network Music, Spirituality and Wellbeing. ORCID: https://orcid.org/0000-0003-0663-4693. E-mail: b.inglis@mdx.ac.uk 


\section{APPENDIX: Interview with Kate Ryder}

Young Vic Theatre, London, 10 June 2019

\section{Instruments}

BI: I'd like to ask you, when did you first become a participant in the fascinating world that is toy piano practice?

KR: I was thinking about this. Back in Sydney in the 1980s I had been aware of [John Cage's] Suite for Toy Piano but at the time I didn't have a [toy] piano, so I might have even played it on a big piano as a little diatonic exercise. But it wasn't until about 2005/2006 I started collecting them.

BI: So the repertoire - the Cage suite - in a sense led you to the instruments?

KR: Yes, I think so. And also performances. I was doing a performance for one of the Cutting Edge series concerts. ${ }^{5}$ Roger [Redgate] wrote me a piece for toy piano, prepared piano and music box. ${ }^{6}$ So it was really for that reason that I started to focus on them, and the first one I ever found was in an antique shop in Crystal Palace [south London], and it was a tiny little thing, kind of Dorian mode, painted keys, not particularly useful! But I had it restored, painted nicely, and it just sat there rather adorably. So that kick started it. I ordered a Jaymar on eBay (it was much easier in those days.) And then I did another Cutting Edge series in which I commissioned a lot of pieces for the instrument, and one of them was by Catherine Kontz, called Siegfried E๑ Melusina [2008], based on I think an Icelandic tale. And it was very interesting, as Catherine's pieces are, a little theatre piece, a modular piece in fragments, which had text, puppets, and a personalised music box.

BI: So when you acquired the piano from the antique shop in Crystal Palace was it the sound of the instrument that captivated you or its possibilities?

KR: I would say the sound and the individual character of each; they're all so different. And my attraction has not been to the modern manufactured mini grand pianos, although I do have one and they're wonderful.

BI: So the sound of the antique instruments, and also their individuality, is the key thing here isn't it; their uniqueness, and the fact that they're not as commodified or homogenised as the major modern brands.

KR: There's an interesting thing about them: each one is a piece of visual theatre. It's not just the sound, though each one does have a distinct sound, like found objects, which has always interested me, a bit like percussion. A lot of the instruments I've bought I'd say are slightly disabled, you know they'll have one note that doesn't quite work; for example they'll have a very flattened 7th, or there'll be a scale that's slightly wonky. That to me is very appealing.

\footnotetext{
${ }^{5}$ A concert series run by the British Music Information Centre in the 2000s at The Warehouse, Waterloo (London, UK).

${ }^{6}$ Koan for toy piano, prepared piano and music box, 2007.
} 


\section{Characteristics}

BI: That's interesting because that's something that Pestova (2017, p.31) picks up on, the fact that the tuning is unstable. That's something that might concern some performers and composers and excite others. It sounds like you fall into the latter category.

KR: You see I wouldn't agree with that. I don't think that the tuning's unstable. The tuning is stable, but it's not regular tuning.

BI: It's not homogenised?

KR: It's not homogenised. For example, I would say the prepared piano was unstable, because you can't tell from one instrument to the next what you get. And also, as you prepare, you might do it slightly differently. With the toy piano, what you get is what you get. You do have fixed range - you'll have many different ranges. Of course the other thing is the articulation. This is an interesting challenge because of the way I put them together (stack them) which is a unique way to do it.

BI: So it's a little bit like the registers of an organ, would you say; you're using them like ranks and registration?

KR: More like manuals of a harpsichord, where you might have a buff stop. In a way that is interesting to me, rather than playing one diatonic instrument.

BI: That's a way of extending the range and the sounds as well, I guess.

KR: The point I want to make is that that is what is interesting to me. It's the uniqueness of the antique instruments. Although the Schoenhut company sent me a beautiful 3 octave grand, which is a fabulous theatre piece in itself. I've had two from them actually and the latest one they sent me was for a concert in 2015 at Wellcome Trust [London]. It's a lovely instrument and very responsive. They've made improvements, because they know that it's out there as a performing instrument; they no longer think of it as just for kids.

\section{History}

BI: That is interesting. Because obviously you have the Cage, an iconic piece from the 40 s written for a dance by Merce Cunningham; that's a specific context. You then have things from the 1970s like Hugh Schrapnel and the Promenade Theatre orchestra using toy pianos and reed organs. But it seems to have emerged as a solo instrument quite notably since the 1990s. Why do you think that is?

KR: Maybe the interest composers have in writing for them, and the availability of new pieces. There were some seminal pieces then. Like those early commissions for Margaret Leng Tan (who was really one of the first pianists to embrace it as a solo instrument), like Stephen Motague's Mirabella, those pieces are little classics - almost in the same vein as the Cage suite. And her wonderful little CD. ${ }^{7}$ So they're played by everybody; I've played Mirabella many times over the last decade. Another one is

\footnotetext{
${ }^{7}$ The Art of the Toy Piano, Point Music, 1997. Includes original compositions for toy piano by Stephen Montague, David Lang, Jed Distler and Julia Wolfe.
} 
by Errollyn Wallen, also written for Margaret Leng Tan, which is based on little ornamentations and fragments of Louis Couperin. ${ }^{8}$ It's a very popular piece and can also be played on piano, and I've done it both ways. It was handwritten and very much in the vein of writing something quickly for someone, you know - I think Margaret wanted a piece overnight. But it's a very skillful, witty little piece. So things like that, as far as I'm concerned they're classics.

BI: So you'd say it was performer-led, and that leads then to repertoire; people writing pieces.

KR: To repertoire, that's right. Another is Austrian pianist Isabel Ettenauer. But they were really the first two pianists who started pushing the instrument, if I can put it like that. The Karlheinz Essl pieces with electronics 9 were written for Isabel. So many of those initial, quite successful pieces, were written for Margaret, and for Isabel, back in the 90s. I was aware of them, but I wasn't immediately attracted to them, until the early 2000s, when I started commissioning.

\section{Practice}

BI: So how do you see toy piano performance relating to other areas of keyboard practice - yours specifically, and the field more generally?

KR: Well in mine specifically I've always been interested in extended sounds, working to add things to the piano. Definitely for me the prepared piano, and electronics, came first - particularly the prepared piano. And so I think again, coming out of Cage and his prepared piano pieces and what he was writing for in the 1940s, the toy piano seemed an absolutely natural extension for him. Seemingly simplified, writing for smaller forces, working with smaller forces, is a kind of discipline. But for me it was always about the sound, and adding instruments to instruments as well.

BI: Yes, I think with Cage it was part of his aesthetic of objectivity and restraint wasn't it, and I guess the fact he had a 9-note mode to play with relates to some of his earlier pieces from the 1930s.

KR: I think that's true, but also with Cage, he'd been writing for quite large forces. Obviously the prepared piano occupied him almost totally in the 40s. But I think it was somehow the discipline, where there are constraints, and being imaginative within those constraints.

BI: So with the toy piano as an instrument obviously there are strengths and weaknesses. We've talked about some of the weaknesses (if they are weaknesses)...

KR: You see I wouldn't say they are. Again I come back to the idea of the tuning. It can be slightly microtonal, and I think for me that's a great attraction. And I think for very interesting composers that's a great attraction. The fact that the pitch isn't exact. But it is stable. There are other examples where it's much more difficult on toy piano. Repetitions, tremolo can be tricky, particularly on old instruments. Notes can stick - if you talk about anything being unstable, that's the biggest thing. So anything that's really robust I tend to do on the bigger, modern instruments. Obviously you can't use pedal. You have to be more precise. And the other areas are, of course, dynamics. You can still make subtle differences.

\footnotetext{
${ }^{8}$ Louis' Loops (Peters Edition, 1999).

${ }^{9}$ Kalimba, op cit; Sequitur $V$ for toy piano and live electronics, 2008.
} 


\section{Performance \& composition}

BI: So this brings us to performance \& composition and the relationship between the two. Because it seems to me that the toy piano, like the prepared piano, problematises the sign-sound relationship you don't know necessarily exactly what you're going to get, particularly from one instrument to the next. Which is very interesting.

KR: Are you talking in terms of what - audience?

BI: No - in terms of composers and their relationship with performers. For instance if you're writing for prepared piano, as a composer you need to work very closely with a performer. Would you say the same applies to toy piano?

KR: I would. I'd say it's very much part of the experimental genre of instruments. I would say certainly for composers writing specifically for that format, there is, as you know very well, that important interim stage. The first step is to listen to the instruments, and there's the other major step of trying things out, saying does this work? and being delighted when it does work!

BI: I found in that sense it's similar to writing for certain types of percussion, the more unusual percussion, and things like sound sculptures which as you know I've done with [the late artist and sound sculptor] Derek Shiel. And my first encounter with him, having decided that we would work together, was going to his studio to try out his various sculptures and the sounds they made and make recordings; there were pictures of course as well. With what we did you had the briefing sheets with the ranges, and I went round to your house, took pictures and made recordings.

KR: That's essential really.

BI: Yes, if the instruments are all individual.

KR: So of course these days technology can send sound files of individual instruments, but that's an essential step, and - they shall remain nameless - but I did lend a composer (and I rarely do this) an older instrument, one of the first Schoenhuts that I'd been sent, so I didn't miss it. But it wasn't, I don't feel it was a success, because there wasn't this interim stage, to try things out. So I think it has to be seen in that experimental genre.

\section{An authentic repertoire - performance practice}

BI: On your website you talk about creating an authentic new keyboard repertoire for toy pianos, it seems in particular vintage toy pianos, as we've discussed. So could you expand on what this might be, this authenticity, within the context of discussing repertoire more generally?

KR: The exciting thing is people use toy pianos for different things. There are those in America particularly who'll play Mozart and bits of Rachmaninoff - that doesn't interest me at all. And so for those of us who are working with it as a contemporary instrument - a new instrument - the really fascinating thing is building a new repertoire. That's a very exciting thing for me. In a sense you're building a unique repertoire, through commissioning and people writing for you, which is very much 
your own. I suppose authenticity in this context means really that it's written specifically for these instruments and for me, my personality, how I might stack them and how I might do them. A lot of repertoire I've had written for me has been specifically for my instruments. It doesn't mean that they couldn't be played - and many of them have been played - by other performers. (And it's not that, in my own case, I'd never play music written for anybody else.) But they will have very distinct soundworlds. I think people who write for me know my openness to experiment with different genres, specifically genres, because I'm not ever genre biased as you know, I'll try lots of things; something with a rock base.

BI: Like the Julia Wolfe piece. ${ }^{10}$

KR: That wasn't written for me, but I couldn't resist the toy boombox, it appeals to my sense of humour.

BI: Yes, that's something that comes out in toy piano performance isn't it, humour, quirkiness.

KR: Quirkiness and humour, yes definitely. But not to be confused with not taking it seriously, a bit of a joke. I think particularly when you're working with instruments that are originally toys, you have to have a serious approach, because the composers I work with have never treated them as some kind of joke, but as an alternate soundworld, and that's the difference.

BI: Which would link with their presence in the experimental tradition.

KR: Just to add to that, talking about repertoire, and pieces I've commissioned, pieces seem to roughly fall between two stools. There's the kind of, what I would say, the wind chime/lullaby school, childlike school - not that the writing's childlike - of toy piano writing. Pieces called somebody's lullaby, little waltz for so-and-so.

BI: So it's a sort of childhood topic rather than childish?

KR: Indeed, referencing always childhood and the toy. And there's another, treating it very much as an extended instrument, an extension of the piano as well. ${ }^{11}$ Don't forget there's a very interesting piece by Walter Zimmerman, The Missing Nail at the River for piano and T.P. ${ }^{12}$ which the concert pianist Nicholas Hodges has performed.

BI: That's interesting, because when toy pianists are mentioned it tends to be women who specialise in this area rather than men.

KR: You would think so, but maybe they're the ones that get the attention, because I've found a lot of guys do it as well. Again, can I just say - in a way - that's an image I wanted to get rid of right away.

BI: You mean the cute image?

KR: This sort of sweetly playing the toy piano in a smock. This is one of the reasons that I often stand a little bit like a rock musician, with keyboards stacked around me. I commissioned a piece from a

\footnotetext{
${ }^{10}$ East Broadway for toy piano and toy boombox, 1996.

${ }^{11}$ These observations on repertoire are borne out by Loffredo $(2018$, p.100): "Note that many composers so far have drawn strongly on childhood associations, enhanced by the childish chime-like sound of the toy piano. Other composers have considered the instrument from completely different perspectives, both by focusing on the sonorousness of the instrument (but far from any childhood relationship) or by bringing to light other possible associations.”

${ }^{12} 2003 / 4$.
} 
jazz musician, Tim Richards ${ }^{13}$ which was for all my pianos, and it used loops; a very complex piece to play. Incidentally I took all the instruments including the looper to Russia, to St Petersburg. I think that was almost the end of my touring with toy pianos, so exhausting doing that! In a way the freedom of standing and playing is much more liberating than sitting down.

BI: And it's not something pianists are used to. How do you find audiences respond? because one of the things about toy pianos is you can do it in locations which don't have a big piano; it enables pianists to access more interesting and more unconventional spaces; even outdoor spaces.

KR: Well I did a festival down in the [English] West Country, a rock festival; that was pretty crazy! That was in a big coloured tent. The amplification of them is something I should mention, that needs to be factored in; that's another big thing.

BI: That would add another different element, and I guess with that there's the potential to manipulate sound. So that links with the theme of extended sound sources.

KR: We have these tiny little instruments, reasonably small, and yet you have all these tremendous logistics around them, because really if you're going to work in a big hall you need - particularly if you're going to work with soundtracks - you need to amplify the instruments. So in a way that's one of the most fascinating things about it, that you've got these tiny instruments which should be very simple and actually we've added this massive layer of complexity to it.

BI: And I suppose composers as you said relate to and approach the instruments in very different ways. Obviously as part of your practice you've asked people to write pieces, and commissioned pieces from many composers. Could you talk about some of the people you've commissioned, and pieces which have been written for you?

KR: Well I'd say the earliest pieces were this piece Koan from Roger Redgate, which used a specific music box as well, and the pitches worked around the music box. There's a piece from Yumi Hara [Cawkwell], called Farouche [2008], where she later added a massive drum solo at the back, in the background, which I think is hilarious, because the actual melody was using a specific one of my instruments, the red-golden Jaymar (completely unique) and that was very witty, whether she intended it or not - this very simple piano line and then with this massive Japanese rock drummer in the background

BI: With live drums?

KR: No - they were live, but recorded; piano and CD playback. The piece by Catherine Kontz, of course; the piece commissioned from Tim Richards with many instruments. (I've got so many of them!) My friend from Sydney, Elena Kats-Chernin, wrote me a little waltz, which I premiered on [London's] South Bank for a multi keyboard festival. Errollyn [Wallen] wrote me a tiny little piece too. I have to say also that I played a whole collection of pianos in the Tête-à-tête music festival, the opera festival, ${ }^{14}$ called vocal motions; it was a theatre piece and a lot of that involved improvising on the instruments as well, which I've used quite a bit.

\footnotetext{
${ }^{13}$ Syzygy, 2010.

${ }^{14}$ Founded in London by Bill Bankes-Jones in 2007, originally at Riverside Studios Hammersmith.
} 


\section{Four Pieces for Toy Piano}

BI: So if we could move on to the pieces you commissioned from me, the Four Pieces. These pick up on some of the themes we've explored so far. One of them as you know uses text and voice; one of them uses graphic score and another sound source, field recordings.

KR: In a way you seem to experiment with lots of genres, which I find very appealing.

BI: Yes, also some of the music is quite complex, and some of the music is more simple. So would you say there were any specific sort of challenges and/or pleasures of preparing and performing them?

KR: Well I enjoy working with my voice and I absolutely loved Laugh, wonderful, because it enabled me to go crazy really within a certain discipline; a delight.

BI: Yes, there are paramaters but it allows the performer a lot of interpretation. So as you know the text is by Derek Shiel, itself inspired by Boccioni's painting La Risata. I hadn't actually considered using voice, it just happened; this piece occurred very spontaneously one day, it was just dashed off like you say some [toy piano] pieces have been. And I thought, why not just speak the test as well. The notes are actually based on the letters, they're transcriptions using a sort of musical cipher à la Schumann and Messiaen. So I thought that would be a way of both extending the sound palette and also making it fun. Which it is, and I'm looking forward to performing that myself in Italy, ${ }^{15}$ although slightly scared!

KR: It's not simple.

BI: No it's not as easy as it seems at first, and I will have to practice quite a lot.

$\mathrm{KR}$ : This is the thing, they're not easy.

\section{A serious toy instrument}

KR: Playing on toy piano isn't easy - and to actually get academia to take it seriously. Over many years I've done workshops using toy pianos, and having people write for them, I've got quite a body of music written by students.

BI: It's something that the students seem to be very interested in, along with prepared piano, which is perhaps a related thing.

KR: It's re-inventing something; listening to something differently. We come back to this whole thing about it all - if you're giving restrictions to a composer, this can force them to be more inventive; it can be quite inspiring.

BI: Absolutely, it goes back to Stravinsky dictum, through Cage, as we discussed. And this thing of a toy becoming a serious instrument, do you think that's linked to the experimental tradition and its aesthetics, valorising the marginalised?

KR: I think Cage validated it immediately, because by that stage [of composing Suite for Toy Piano

\footnotetext{
${ }^{15}$ At MUSIC AS PLAY, 2019, Como.
} 
in 1948] he'd won the argument with prepared piano for a decade.

BI: He had an inclusive attitude to sound; nothing was excluded.

KR: Further, composers like Karlheinz Essl started adding electronics and playback. Another person I should mention is Stace Constantinou, who wrote that piece [Cactus Prelude No 6] originally for piano but then did a version for toy and electronics. He was using Max MSP, which is quite funny when you consider this tiny little instrument and this sophisticated programme. But I think all that kind of thing validates the fact that people put it into the context of concerts, as I try to do, with other instruments, with [concert] piano.

BI: There are earlier precedents like the Leopold Mozart toy symphony, ${ }^{16}$ but that seems to treat toy instruments as a bit more of a joke. ${ }^{17}$

KR: I would say the essence of it is, not to be pretentious about it, because in a wonderful way it cuts through any kind of pretention. But to take it as an instrument; it is an instrument, and not a toy.

\section{Graphic notation for toy piano}

BI: Let's move on, via talking about the fourth piece in my little suite, Water and Stone, which as you know is notated using a graphic notation. Obviously you have experience of interpreting graphic scores, not only on toy piano but in other contexts too. Do you have a specific approach to them, or does this vary from score to score, because there are different types, as we know.

KR: There are many different types. For me it's interesting whether they're purely [indeterminate] graphic scores, or whether it's pictographic; the graphics are just another form of quite specific notation.

BI: Yes, you can get symbolic signs and pictorial signs; pure ones and different types of hybrid with conventional notation.

KR: I would argue that they're not graphic, that they are simply other forms of notation, some of the Lachenmann pieces, whereas I think something like Water and Stone gives a lot of leeway and yet in some ways is incredibly difficult. I have to admit, I found this the most difficult of all the pieces you wrote.

BI: Is it the co-ordination with the track? Or the interpretation?

KR: It was delightful you had a track that was a wash of sound.

BI: Ah yes, there's not much to synch with, apart from the shift in the middle from one kind of sound to the other.

KR: And this is one where, in a sense, absolutely, you would have to work closely with the composer. Unless you had a composer who said, do whatever you wish, interpret it as you will, you can turn it upside down.... But in terms of this one, having to play it within a certain timeframe - graphic scores

\footnotetext{
${ }^{16}$ The attribution of the Kindersinfonie is in fact uncertain. Historically it was attributed to Joseph Haydn, and more recently to Edmund Angerer, but no definitive attribution has been established. See Loffredo 2018, pp.34-35.

${ }^{17}$ See again Loffredo's observation on humour and toy instruments, quoted earlier (2018, p.101).
} 
like this are actually quite tough. People wrongly assume that it's free interpretation, quasi improvisation. I don't think it's free at all because here, the timeframe, and the fact that there is a physical score, limits your interpretative abilities. Because you're always slightly concerned in a performance with when it's got to move on; whether or not it's getting slightly stuck.

BI: I think it's freeing in some ways, but it's not a free-for-all, that's true. And I think most composers of graphic and text instruction scores don't want it to be a free-for-all, including Cage, he was very resistant to that.

KR: Most good composers, yes, serious ones. You see with a lot of students (mind you I've had some fabulous scores from students over the years with brilliant ideas) I think where they fall down is by often not having clear instructions.

BI: Or at least a clear sonic vision in their mind, however that's expressed.

KR: If I were composing a graphic score I would always bear in mind that somebody on the other side of the world might be playing it, and we might not have very good internet access! Therefore the composer needs some kind of clear expression of intent. Of course some composers like Earl Brown, Lou Harrison, Christian Wolff, deliberately obfuscated the instructions.

BI: Encoded ambiguity?

KR: Exactly, encoded ambiguity; deliberately ambiguous. In which case the composer has to be prepared to accept what comes out of that. You can't say "I didn't mean it to be like that", in which case I would say, "Write it as you mean it to be".

BI: I guess with this graphic score, you're right, in a way it is quite specific, with the cluster notation, the various types of trill, notes of different durations, and the quite specific timescale. Having practised this myself with the track, I think it's best not to count it and just feel it, which is the conclusion you came to when you were performing and recording it.

KR: I did. In a way I gave myself a little leeway and I said look, you know what, it's better that I go for it.

BI: Yes, and in that sense it is liberating.

KR: It's kind of a guide.

BI: That's the thing. It's not as specific as it would be in conventional notation, but it's not a complete free-for-all either

KR: Or indeed with a [more synchronised] tape part.

BI: What I was also interested in, it's quite an efficient way of notating things like clusters, particularly clusters which are expanding and contracting. You get this a little bit in Schumann, not with clusters obviously but there are those pieces where you lift each note of a chord. In conventional notation that's quite clunky and cumbersome, but in graphic notation it's very easy and very visual and direct. You get that in Cage's Concert for Piano and Orchestra and in Ligeti's Volumina as well. You start with one note and you gradually add, diatonically or chromatically. And there's nothing more visual or dramatic than notating a full arm cluster with that [a filled-in vertical rectangle - see score page image in Figure 10, beginning of last system]. It's very satisfying to play and notate. In using the clusters I was trying to get away from that cute thing you talked about, and just explore the 
instrument as another sound-source. It's also very interesting playing clusters on the toy piano.

KR: Especially if they're amplified!

BI: It's been said that thick chords don't work that well because of the inharmonic resonance and richness of that, but of course with a cluster you're aiming for saturation; it seems to work very well.

KR: Who's to say what works well and what doesn't?

BI: Quite, everyone has their own idea about that, it depends on the person and the aim.

KR: For me they [clusters] work better on the toy piano than on the big piano.

BI: Because they're more subtle and less masculinist? There can be something macho about very loud, very big piano clusters, perhaps!

KR: That's a whole other ball game!

\section{Concluding thoughts for composers \& pianists}

BI: Finally - do you have any tips for composers wanting to write for toy piano, and pianists who'd like to acquire and work with them?

KR: For composers, in the first instance you've got to be enthusiastic about the instrument; you've got to find out the ranges. The ultimate, professional T.P. - which so many pieces have been written for - is three octaves from F below middle C. That's a standard concert instrument. A lot of the instruments including the Jaymar might go from middle $\mathrm{C}$ to F. For many other pianos it's just middle $\mathrm{C}$ to $\mathrm{C}$. I think probably the piano Cage originally worked on was just 2 octaves, $\mathrm{C}$ to $\mathrm{C}$. And then you need to be aware that it doesn't respond like a piano. It's not like a celeste, which is very heavy. A little bit like clavichord, but that's a much quieter instrument and it's an entirely different mechanism. I try to think of it as a unique instrument of its own. For performers, it's still very appealing to look around junk shops, antique shops and car boot sales. Toy pianos are still out there, and you have to like them as (found) objects. If you want to be more specific and play the Cage Suite for Toy Piano, which is a great place to start, you can buy them in toy shops. Some of them aren't particularly marvellous - I personally wouldn't go for anything less than two octaves, C-C. I must say they don't like being moved around very much! To take mine to Sydney I had a flight case made at some expense. In Russia I thought I'd be hauled off by security at the airport, but I knew the Russian words for "toy" and "play" and it was fine. In Hong Kong, getting through security - imagine the cameras - they saw these spindles at the back which looked like knives! And they asked "would you mind opening your case?” ... and I said all it is, is a musical instrument - I had to demonstrate in the airport! It was a bit of a surreal moment. And of course they were all smiles and thought it was absolutely marvellous. 